\title{
Study of the Physical and Mechanical Properties of Coconut Spathe Fiber Reinforced Obsolete Polymer Composites
}

\author{
Rabeya Akter'1, Budrun Neher ${ }^{1}$, M. A. Gafur ${ }^{2}$, Rakib Hossain ${ }^{3}$, Farid Ahmed ${ }^{1}$ \\ ${ }^{1}$ Department of Physics, Jahangirnagar University, Dhaka, Bangladesh \\ ${ }^{2}$ Pilot Plant and Process Development Centre, Bangladesh Council of Scientific and Industrial Research, Dhaka, Bangladesh \\ ${ }^{3}$ Department of Physics, Bangabandhu Sheikh Mujibur Rahman Science \& Technology University, Gopalganj, Bangladesh \\ Email: ^budrunneher@gmail.com
}

How to cite this paper: Akter, R., Neher, B., Gafur, M.A., Hossain, R. and Ahmed, F. (2021) Study of the Physical and Mechanical Properties of Coconut Spathe Fiber Reinforced Obsolete Polymer Composites. Materials Sciences and Applications, 12, 223-238. https://doi.org/10.4236/msa.2021.125015

Received: February 28, 2021

Accepted: May 17, 2021

Published: May 20, 2021

Copyright $\odot 2021$ by author(s) and Scientific Research Publishing Inc. This work is licensed under the Creative Commons Attribution International License (CC BY 4.0).

http://creativecommons.org/licenses/by/4.0/

\begin{abstract}
Fiber-reinforced polymer (FRP) composites have gradually gained wide acceptance as engineering material applications due to their unique advantages including their high strength-to-weight ratio and excellent corrosion resistance. This study was carried out with composites prepared by hot press molding method using coconut spathe fiber as reinforcing material and HDPE (from HDPE can as obsolete polymer) as polymer matrix. Composites were made at $150^{\circ} \mathrm{C}$ under $60 \mathrm{kN}$ load by taking diverse weight percentage (wt.\%) of fiber from 0 to 20 of its total weight. In this research investigation, different properties of the composites such as bulk density, water absorption, tensile and flexural properties, impact strength and hardness test properties were carried out. The fiber content enhancement increases the bulk density in all composites. The rate of water absorption improves with the improvement of fiber addition with respect to HDPE in all composites. But the water absorption was not increased uniformly with the increase of fiber addition in composites. In all cases, composites absorbed water very rapidly up to $80 \mathrm{hrs}$ and then water absorption is in saturated condition. The mechanical properties like tensile strength (TS), flexural strength (FS), impact strength (IS) and hardness were observed to be comparatively more enhanced for $5 \%$ composite, while further increasing of fiber addition, all mechanical properties changes irregularly. The irregular nature of change might be caused due to the over loading of fiber in polymer matrix.
\end{abstract}

\section{Keywords}

Coconut Spathe Fiber, Obsolete Polymer, Matrix, Tensile Strength, Impact Strength 


\section{Introduction}

In composite materials, the usage of natural fibers has increased day by day, because they execute the sustainability criteria for development, are enthusiastically available at a cheap expenditure from the renewable sources and advantaged over synthetic fibers as reinforcement [1] [2] [3]. Over the last few decades, natural fibers reinforced polymeric (NFRP) composites material was used as a significant development of cellulosic material, because of its wide range of applications and their excellent sustainability, biodegradability, low density [4] [5] [6] [7]. To harvest sustainable composites for numerous applications, some researchers suggested with the idea of emphasizing diverse natural fibers in polymers matrix [8]. Natural fibers like henequen, sisal, jute, coir, etc. make them attractive as reinforcing materials for the substitution of engineering artificial fibers because of some beneficial physical and mechanical properties [9] [10] [11] [12]. Moreover, in order to save energy in several industrial applications, unfilled tubular structure of natural fiber enhances their acoustic and thermal insulating properties [13] [14] [15] [16] [17]. A huge amount of coconut wastes, roughly estimated $12.75 \mathrm{t}$ dry lignocelluloses residues, are produced yearly from husks, spathes, peduncles, petioles, leaves. This provides a bright prospect for utilizing these residues and panels production for the construction industry [18]. The covering of the coconut inflorescence used as coconut spathe fiber in this research, is an under-exploited material with significant prospective in this respect. Research has been done with coconut palm (Cocos Nucifera) and different part from coconut palm tree, as like as, rachis, rachilla, spathe, root, coir have been examined and concluded that all parts can be used in composite, leaf bud sheath, coir, shell [19] [20] [21] [22].

Nowadays, the natural fiber demand as renewable materials for the reinforcement in polymer composites has been increasing. Yearly, $15 \%-20 \%$ in automotive applications and more than $50 \%$ in construction applications, the rest being in the manufacture of tiles, furniture, sea platforms, etc. are used natural fiber as strengthening factor in polymer composites [23]. Because continuous use of plastics and plastic products in everyday life plastics waste increased day by day, now it is necessary to recycle and reuse the plastic products [24]. Most exceedingly demanded plastic is high density polyethylene (HDPE) and the plastic products produced from it are the common plastic waste. In the urban areas, plastic utilization has increased drastically from $5.56 \mathrm{~kg}$ per person in 2005 to $14.9 \mathrm{~kg}$ per person in 2014 and increased the amount of wastes also [25]. In this present study, composites were made from obsolete high density polyethylene (HDPE) as polymer. HDPE in pure condition is a thermoplastic polymer having good physical and mechanical properties like as low water absorption, better hardness and strength. To reduce the plastic waste from environment and reduce carbon footprint recycling is the best way [26]. The density of pure HDPE is greater or equal to $0.941 \mathrm{~g} / \mathrm{cm}^{3}$ and the ultimate tensile strength of HDPE is about $31 \mathrm{MPa}$ according to ASTM D638. Additionally, the melting point is in the range of $120^{\circ} \mathrm{C}$ to $180^{\circ} \mathrm{C}\left(248^{\circ} \mathrm{F}\right.$ to $\left.356^{\circ} \mathrm{F}\right)$ [27]. 
A lot of research investigations have already been accomplished on fiber reinforced composite to gain excellent properties. Mechanical characterization of sisal fiber reinforced HDPE composite was done by R. Chianelli et al. [28] and found that the addition of sisal fibers in composites tensile strength was not increased. The incorporation of sawdust-urea-formaldehyde resin into banana fiber gave the best mechanical properties [29]. And in this case there was proper adhesion-fiber interaction for this best result. Rafia A et al. [30] fabricated woven natural fibre reinforced unsaturated polyester resin composites and observed that the flexural strength and it's modulus enhanced with the increase of talc fiber content. An investigation of the ABS/wood composite by different technique was done by L. Chotirat et al. and perceived that the enrichment of wood achieved very good composite properties [31]. The viscosity of composites improved with the rise of wood content when $M$. Kaseem and his co researchers investigated [32]. Another research group P. Threepopnatkul and his co-workers were investigated the similar property and they found very good properties of the composite [33]. The fiber content increased the stiffness of the composite was found by Johnny N. Martins et al. when they investigated various properties of ABS/textile fiber composites [34]. Mohammad N. N. B et al. [35] fabricated kenaf fiber reinforced rPET/ABS composites. They observed that over fiber loading increased brittleness of the composite as confirmed by morphological characterization. The understanding of the benefit of natural fiber and availability of coconut spathe fiber has stimulated the current work in which coconut spathe fiber are being developed as new engineering material and recycled HDPE as obsolete polymer is used for leading reusing approach. Coconut spathe fiber reinforced HDPE composite was prepared and different properties are investigated. The physical properties like bulk density and water absorption and mechanical properties like tensile and flexural properties, and impact strength and hardness of the composites were studied.

\section{Materials and Methods}

\subsection{Raw Materials Collections}

In this investigation waste material as recycled HDPE (from HDPE can) was employed as matrix and natural coconut spathe fiber as reinforcement material. For matrix recycled high density polyethylene (HDPE) from colorless HDPE can was collected from local market with a density of $960-970 \mathrm{~kg} / \mathrm{m}^{3}$. And the reinforcing material coconut spathe fiber was collected from local sources by hand from coconut tree.

\subsection{Composite Preparation}

Composites were prepared by hot press molding method for different wt.(\%) of fiber content ( $0 \%$ to $20 \%$ ) in HDPE polymer matrix at $150^{\circ} \mathrm{C}$ under $60 \mathrm{kN}$ pressure. Coconut spathe fiber was collected from coconut tree then washed with distilled water in order to remove inclusions and foreign particles and then dried 
for 2 days in sunlight. After that, the dried fiber was cut into a size of $14 \mathrm{~cm} \times 12$ $\mathrm{cm}$ mat. Cutting samples were then dried in oven for 24 hours to get rid of moisture and to improve bonding. HDPE sheet of equal size of fiber was cut from HDPE can and these pellets were thoroughly cleaned with water and dried for 2 days under sunlight in open air before they were used in composite as matrix. For the hot press two open molding plates of $21 \mathrm{~cm} \times 16 \mathrm{~cm}$ were used. Coconut spathe fiber was kept in between HDPE sheet and spathe fiber reinforced HDPE composites were prepared for 5\%, 10\% 15\% and 20\% compositions. In composites the layer of spathe fiber used in between HDPE sheet for 5\%, 10\% $15 \%$ and $20 \%$ compositions were one to four, respectively. Two molding papers were used to cover and compressed the composite. The mold was then pressed with $60 \mathrm{kN}$ pressure at $150^{\circ} \mathrm{C}$ for 20 minutes and allowed to cool at room temperature. The composition of composites samples are given in Table 1. Raw coconut spathe fiber and HDPE sheet from colorless HDPE can be shown in Figure 1(a) and Figure 1(b), respectively. By using Paul-Otto Weber Press machine composites were made for different wt.(\%) of spathe fiber reinforced HDPE. After the hot press molding operation, the specimen was cut according to ASTM standard and characterized in terms of physical and mechanical properties.

\section{Characterization of Composites}

\subsection{Determination of Physical Properties}

\subsubsection{Bulk Density of Composites}

By measuring the weight and dimensions of the individual sample the bulk density

Table 1. Composition of different percentages of HDPE and coconut spathe fiber in composites.

\begin{tabular}{ccc}
\hline \multirow{2}{*}{ Composites } & Composition weight (\%) \\
\cline { 2 - 3 } & HDPE wt.(\%) & Coconut spathe fiber wt.(\%) \\
\hline C1 & 100 & 0 \\
C2 & 95 & 5 \\
C3 & 90 & 10 \\
C4 & 85 & 15 \\
C5 & 80 & 20 \\
\hline
\end{tabular}

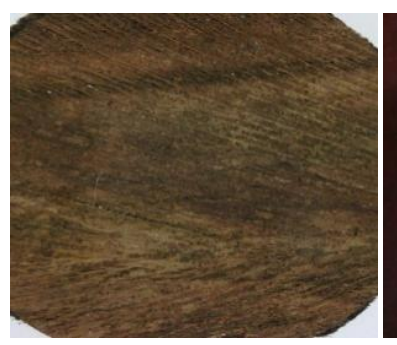

(a)

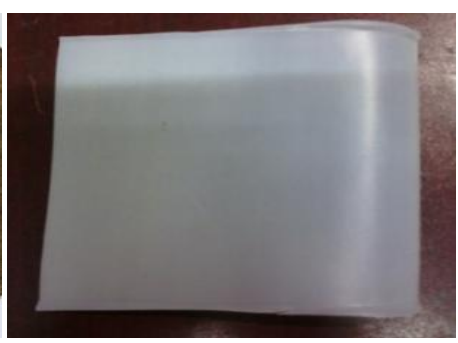

(b)

Figure 1. (a) Raw coconut spathe fiber, (b) HDPE sheet from HDPE can. 
of the HDPE/Spate fiber composite samples were measured permitting to ASTM C134-76 [36] using the following equation

$$
\text { Bulk density, } D=\frac{w_{t}}{L \times W \times H}
$$

where, $w_{t}, L, W$, and $H$ are weight, length, width, and height of the composites. To measure bulk density $50 \mathrm{~mm} \times 10 \mathrm{~mm}$ samples were cut from original samples.

\subsubsection{Absorption of Water of Composites}

Water absorption investigation was done by maintaining the rules of ASTM D570-98 [37]. Sample was taken for $0 \%, 5 \%, 10 \%, 15 \%$ and $20 \%$ ) of water at $25^{\circ} \mathrm{C}$ for different time periods (up to 144 hours). The samples weight was determined before ablution of sample. The following formula was used to evaluate the soaking percentage [38].

$$
w_{g}=\frac{w_{a}-w_{0}}{w_{0}} \times 100
$$

\subsection{Determination of Mechanical Properties}

\subsubsection{Tensile Strength and Flexural Strength of Composite}

The Tensile Strength and Flexural Strength were measured by using universal apparatus (Hounsfield UTM 10 kN; ASTM D 3039/D 3039 M-00) [39]. Tensile Strength properties were measured at $2 \mathrm{~mm} / \mathrm{min}$ crosshead speed, taking $50 \mathrm{~mm}$ as gauge length. Same apparatus were used to determine flexural strength.

\subsubsection{Hardness of Composite}

We have applied Leeb's Rebound hardness test in this project because of it has portability property which increase the testing rates without annihilation of samples and saves cost [40]. A ball hammer of carbide and electronic sensor spring rather than gravity powered and measures the hammer velocity respectively.

\section{Results and Discussion}

\subsection{Physical Properties}

\subsubsection{Bulk Density of Composites}

Before making the composite, the moisture absorption of spathe fibers was reduced as it is hydrophilic in nature. The consequence of the variation of wt.(\%) of spathe fiber on the density of HDPE/spathe fiber composite is illustrated in Figure 2. The bulk density of spathe fiber reinforced HDPE composite increases with spathe fiber addition. The density increases from $0.58 \mathrm{gm} . / \mathrm{cc}$ to $0.88 \mathrm{gm} . / \mathrm{cc}$ for different wt.(\%) of fiber contents in composites. The bulk density is not identical under the similar condition indicated by the figure. Bulk density gives similar value for composites with $5 \%, 10 \%$ and $15 \%$ fiber. After that, the value decreased for composites with $20 \%$ fiber. Bulk density is maximum for $15 \%$ fiber content in HDPE/spathe fiber composite. In this research coconut spathe fiber 


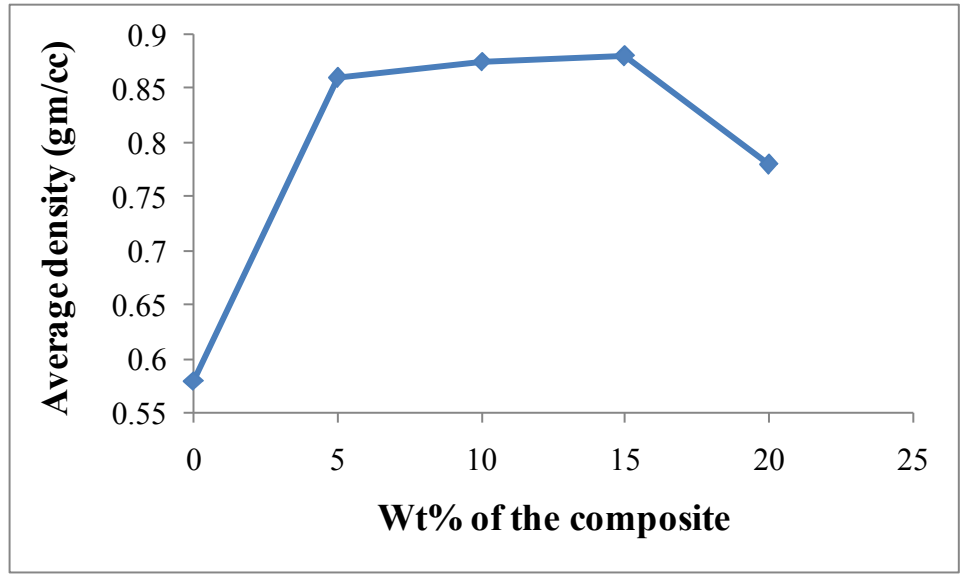

Figure 2. The effect of the variation of the amount of spathe fiber wt.(\%) on the density of spathe fiber reinforced HDPE composite.

was used as fiber which is naturally abundant in our country, Bangladesh. To make the composites cost effective, in this research very natural fiber as mat shape was used and was taken the same weight and size of mat shape fiber. In naturally occurring coconut spathe fiber, fibers are not homogeneously distributed. May be the coconut spathe fiber mat used in $20 \%$ composition had more voids, porosities, and spaces within the components of mat, which may gave lower bulk density for this composites.

\subsubsection{Water Absorption of the Composites}

Figure 3 shows the consequence of the accumulation of fiber content on the absorption of water behavior of the coconut spathe fiber reinforced HDPE composites. Figure indicates that the absorption of water of the composites was observed to improve with the increase of spathe fiber content in composites. Water absorption of the composites was very fast up to first $80 \mathrm{hrs}$ then water uptake slowed down with time. Finally graph shows a flat zone for the rest of the observation time. Moreover, figure indicates that the water absorption increased with soaking time, but the rate of absorption decreased over time for all of the composites. Water absorption by HDPE/spathe fiber composites was not uniform and maximum water absorbed by $20 \%$ composite then $10 \%, 15 \%$ and $5 \%$ composites. The water absorption was lowest for $5 \%$ composite among all composites which means that may be fiber content is lower than other compositions. In this research composites were made with layer by layer of obsolete HDPE polymer (collected from color less HDPE can) and coconut spathe fiber of same shape. The density of fiber is not same all over the volume of the mat shape coconut spathe fiber used in this research. From this inhomogeneous distribution of fiber content in mat shape fiber used here caused variation of water absorption. Also these may results from inadequate fiber content in interfacial side of $5 \%$ and $15 \%$ fiber content composites for absorption of water. Maybe due to these reasons $5 \%$ and $15 \%$ fiber content composites absorbed less amount of water. Naturally, polymer absorb small amount of water while the natural fiber 


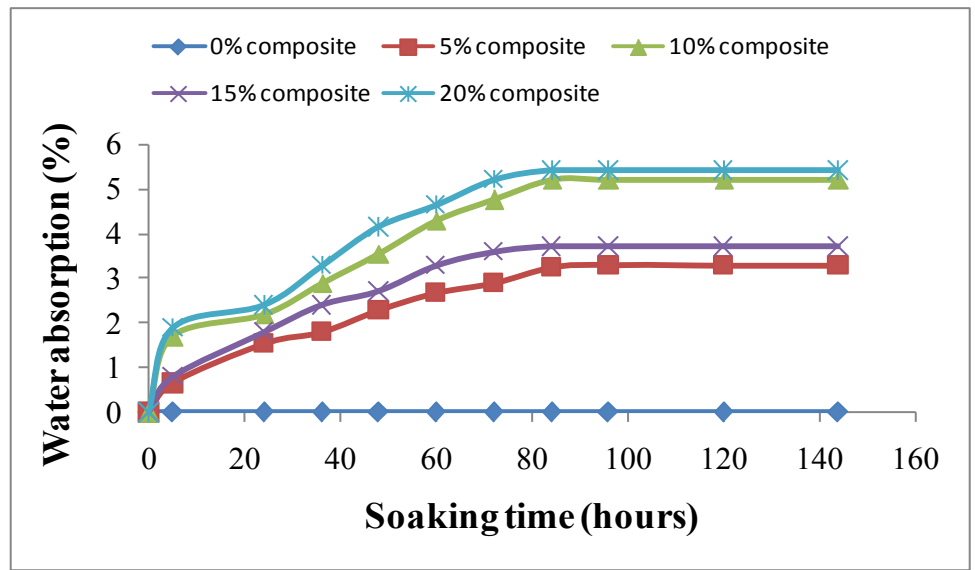

Figure 3. Water absorption (\%) vs soaking time in hours for spathe fiber reinforced HDPE composites.

reinforced polymeric composites absorbs more water due to the hydrophilic nature of the natural fiber (due to presence of polar group). Through the interfacial side of the sample water can enter into the composite which may allow hydrogen bonding to occur between the free hydroxyl groups of the cellulosic molecules with water molecule [41].

\subsection{Mechanical Properties of Composites}

Any chemical or morphological change has an effect on the mechanical properties of the fibers. Due to poor natural fiber-polymer bonding, lignocellulosic fillers have limited use in industrial practice in spite of its attractive properties [42].

\subsubsection{Tensile Property of Composites}

Figure 4 shows the tensile strength of the composites increased with the increase of fiber content up to $15 \%$ then the value decreased sharply for $20 \%$ composites. Firstly with the addition of fiber content in composite, the value increased for $5 \%$ then tensile strength decreased for $10 \%$ composition. After that its value again increased for $15 \%$ composition which is the maximum value for tensile strength. Then the value decreased sharply for $20 \%$ composition giving the lowest tensile strength among all compositions including HDPE.

Seung-Hwan et al. [43] showed that due to poor interfacial adhesion between polymer matrix and fiber the tensile strength progressively decreased with the increase of fiber content. Naturally fibers are hydrophilic and polymers are hydrophobic so it is unable to coexist these two materials in composites. Although, spathe fiber produces initially a significant reinforcement effect in the used HDPE composite. But with the increase of fiber addition in composites the value was in decreasing nature. The maximum value of the tensile strength of spathe fiber reinforced HDPE composites is found to be $20.22 \mathrm{MPa}$ for $15 \%$ spathe fiber. This means that up to $15 \%$ the fibers are well distributed in the composites and the better interfacial bonding between the fiber and matrix. Another study 


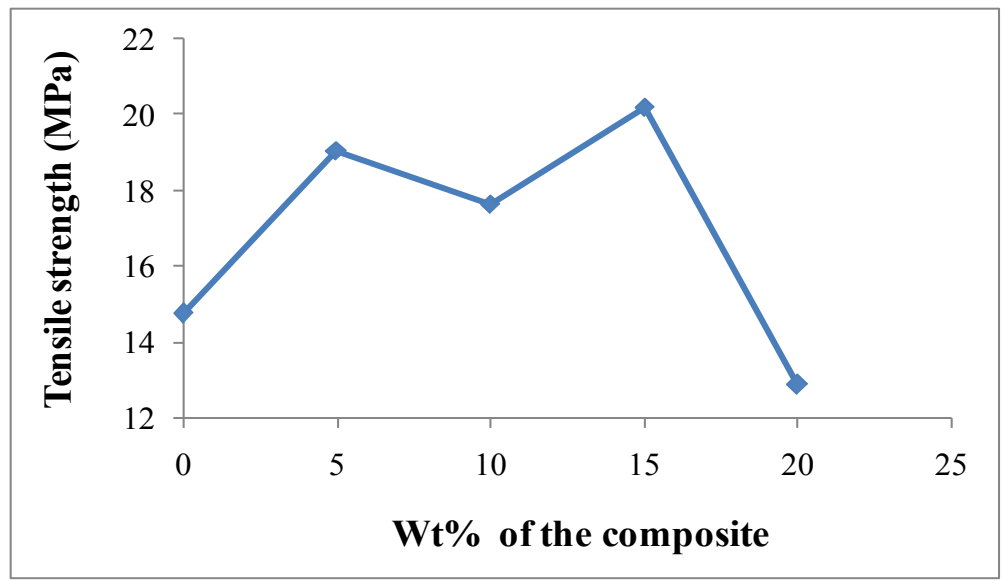

Figure 4. Tensile strength of recycled HDPE/spathe fiber composites with different wt.(\%) of fiber.

showed that due to strong inter fiber hydrogen bonding (which holds the fibers together), when fibers reinforced into thermoplastic matrices they are poorly disperses [44]. Neher et al. [45] investigated that the value of tensile strength was not homogeneous with the addition of fiber in composites. Mohammad, N. N. B. et al. [35] observed that there was a to some extent decrement in mechanical properties with addition of kenaf fiber in kenaf fiber reinforced rPET/ABS composites.

\subsubsection{Elongation at Break (Eb \%)}

The effect of palm fiber loading on elongation at break of composites is shown in Figure 5. In this graph it is shown that with $5 \%$ fiber in the composites the elongation at break (\%)/strain (\%) is maximum. The elongation at break rapidly decreased after $5 \%$ composites with the addition of coconut spathe in composites. The value showed drastically decreasing order when $10 \%, 15 \%$ and $20 \%$ fiber is added into the polymer.

Several researchers showed that with the increase of fiber loading in composites elongation at break decrease. As a result, with the increase in the dispersed phase in composite, the discontinuity of the polymer matrix increases [43] [46].

\subsubsection{Young's Modulus}

Young's modulus of recycled HDPE/spathe fiber composites for different wt. (\%) of spathe fiber is shown in Figure 6. It reveals that the young's modulus increased at first for $5 \%$ composite by giving the maximum value. Then the value rapidly decreased for $10 \%$ composite, again increased for $15 \%$ composite and finally deceased for $20 \%$ composite. The fiber and the polymer seem to be well dispersed for this increasing region. Composites with $10 \%$ fiber content given the lowest value then other composition along with pure HDPE. The Young's modulus is a measure of stiffness of a material. Thus, the spathe fiber reinforced HDPE composites with $5 \%$ and $15 \%$ fiber addition are stiffer than $0 \%, 10 \%$ and $20 \%$ composites. 


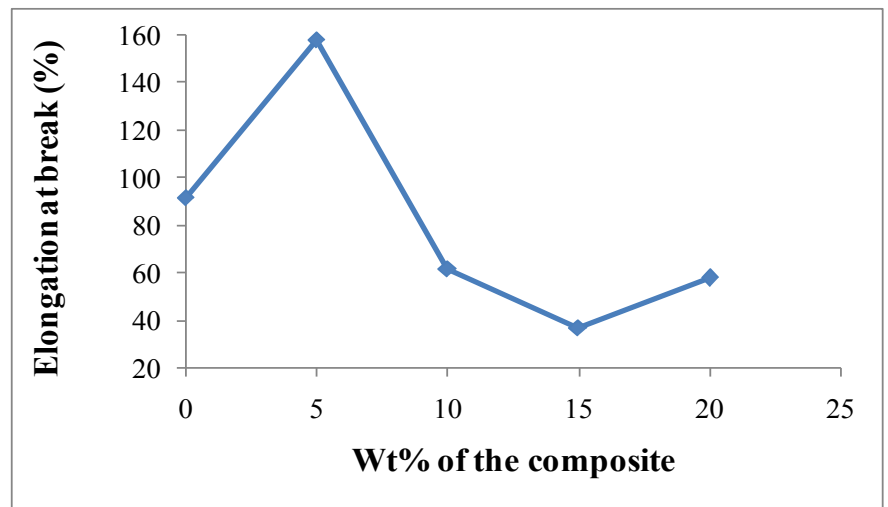

Figure 5. Effect of fiber addition on change of $\mathrm{Eb}(\%)$ for recycled HDPE/spathe fiber composites.

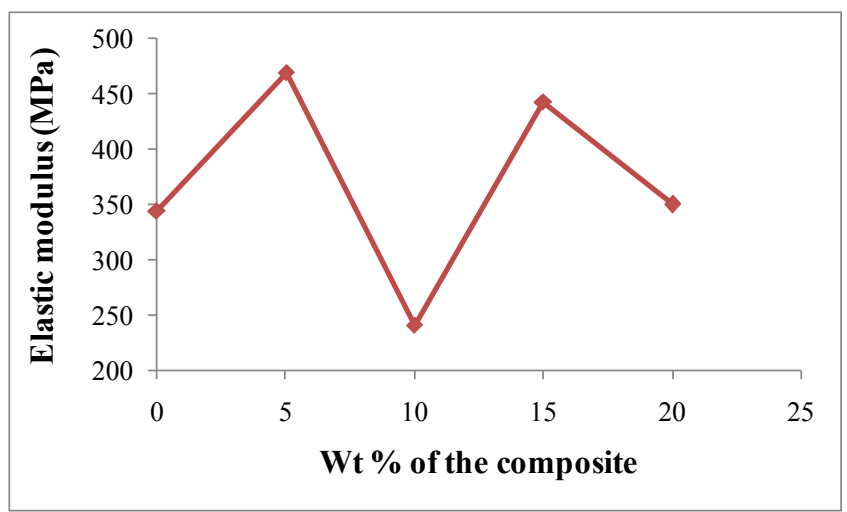

Figure 6. Young's modulus of recycled HDPE/spathe fiber composites as a function of the amount of spathe fabric reinforcement.

\subsubsection{Flexural Strength of Composites}

Figure 7 shows the variation of the flexural trength of coconut spathe fiber reinforced recycled HDPE composites for different wt.(\%) of coconut spathe fiber. Figure revealed that flexural strength of the composites increased with the increase of fiber content in all composites and the maximum value given by $5 \%$ composite. Then the value decreased for $10 \%$ composite again increased for $15 \%$ and finally decreased for $20 \%$ fiber content composites. The abnormal change of flexural strength after 5\% fiber loading in the composite is similar to the research work of Mohammad, N. N. B. et al. [35] in which fiber overloading caused the abnormal behaviour in their kenaf fiber reinforced rPET/ABS composites.

\subsubsection{Flexural modulus of Composites}

Figure 8 shows the variation of the flexural modulus of coconut spathe fiber reinforced recycled HDPE composites for different wt.(\%) of coconut spathe fiber. Figure revealed that flexural modulus of the composites increased with the increase of fiber content for 5\%, 10\% and $15 \%$ composites and the maximum value given by $5 \%$ composite. Composites with $20 \%$ fiber gave the lowest value which was also less than HDPE. The increment and the decrement nature of the value of flexural strength and flexural modulus are similar. 


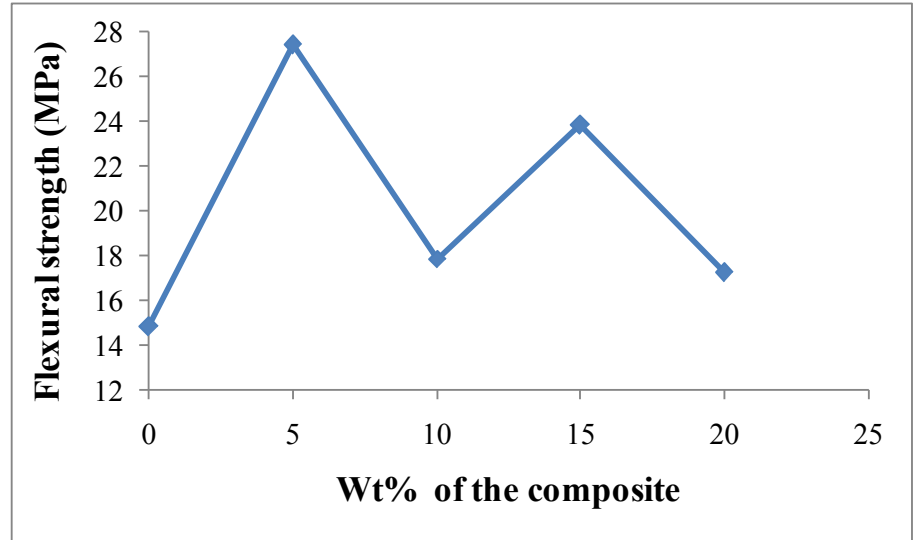

Figure 7. Effect of fiber addition on flexural strength of recycled HDPE/spathe fiber composites.

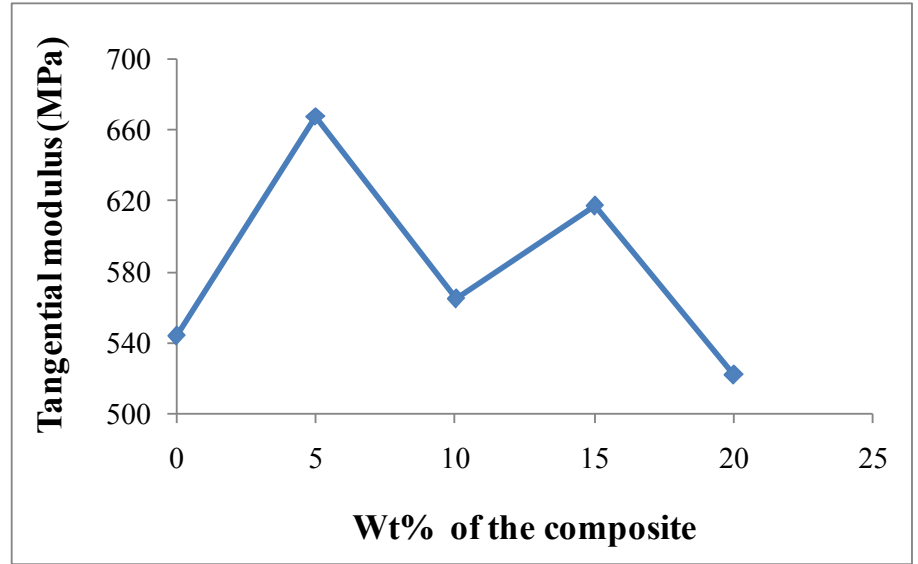

Figure 8. Effect of fiber addition on flexural modulus of recycled HDPE/spathe fiber composites.

\subsubsection{Flexural Strain}

Figure 9 shows the effect of fiber addition on flexural strain of spathe fiber reinforced HDPE composites. As like as flexural strength and flexural modulus, flexural strain also increased for $5 \%$ and $15 \%$ composition and the value decreased for $10 \%$ and $20 \%$ compositions. Maximum value for flexural strain was given by $5 \%$ composites and minimum value was given by $10 \%$ composites. Most of the properties showed better performance for composites with $5 \%$ and $15 \%$ fiber addition.

\subsubsection{Impact Strength of Composites}

Figure 10 illustrates the effect of addition of spathe fiber on impact strength of HDPE/spathe fiber composites. With the addition of fiber content impact strength increased for 5\% composites then the value decreased for $10 \%, 15 \%$ and $20 \%$ composites. Figure shows highest value of impact strength is obtained at $5 \%$ composite. It means that the 5\% spathe fiber reinforced HDPE composite is tough than other composites and lowest value of impact strength means more brittle material. 


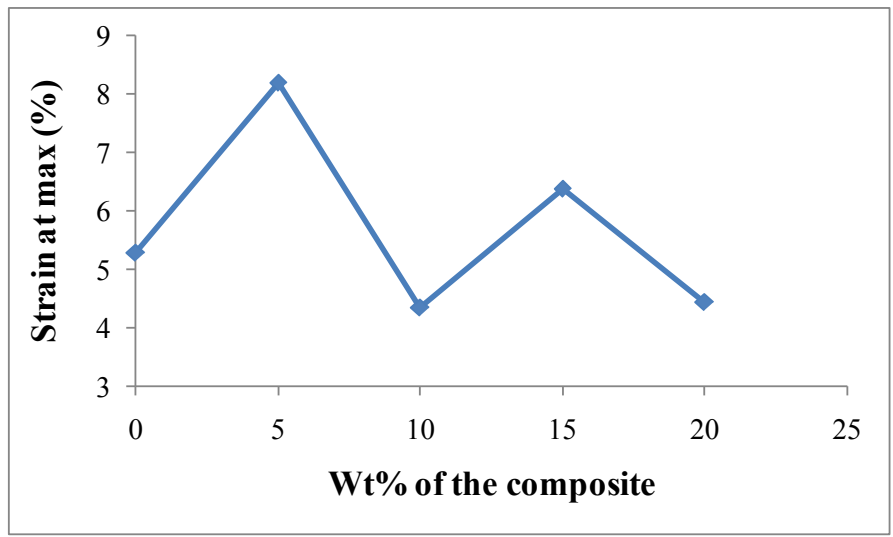

Figure 9. Effect of different wt.(\%) fiber addition on flexural strain of recycled HDPE/ spathe fiber composites.

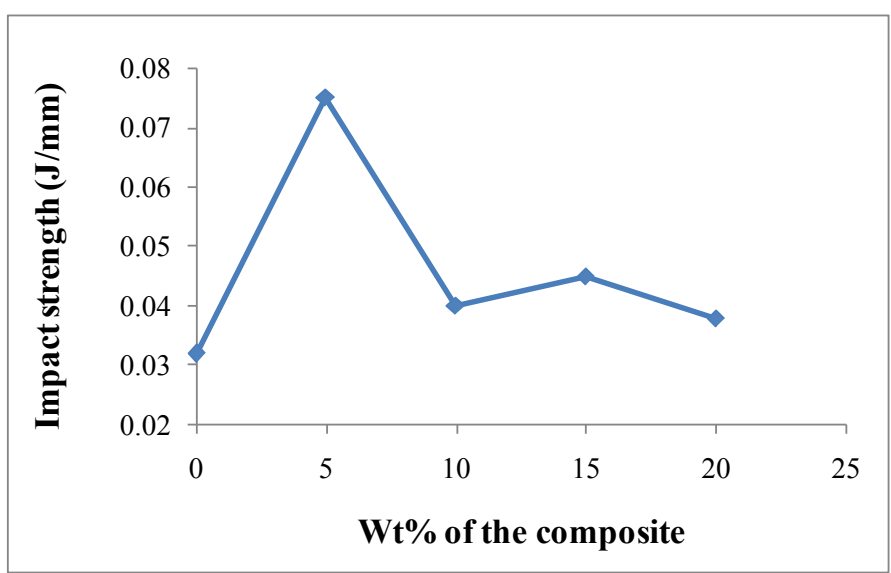

Figure 10. Effect of addition of spathe fiber on impact strength of HDPE/spathe fiber composites.

\subsubsection{Leeb's Rebound Hardness Test}

Figure 11 illustrates the effect of addition spathe fiber on Leeb's Rebound Hardness of HDPE/spathe fiber composites. Results indicated that rebound hardness of recycled HDPE/spathe fiber composites increased with the increase of spathe fiber for $5 \%$ and $15 \%$ composites and the value decreased for $10 \%$ and $20 \%$ composites. Figure shows that for $10 \%$ and $20 \%$ composites hardness decreased drastically. Leeb's rebound hardness test measures the hardness of the material and hardens material produce a higher rebound velocity than softer material.

Tan et al. showed that void are formed in the composites if the composites have a tendency of high moisture absorption and due to this reason some mechanical properties like as hardness reduce in the composites [47]. Another research done by Bhuiyan, A. H. et al. concluded that with the addition of filler $\mathrm{TiO} 2$ in composites, there is a decrement nature of the hardness in the composites [48]. Rahman, M. M. and his coauthor established that as natural fibers are strongly hydrophilic in nature so they absorbed moisture naturally and degraded the mechanical properties of natural fiber reinforced composites materials [49]. Table 2 summarized results for different mechanical properties. 


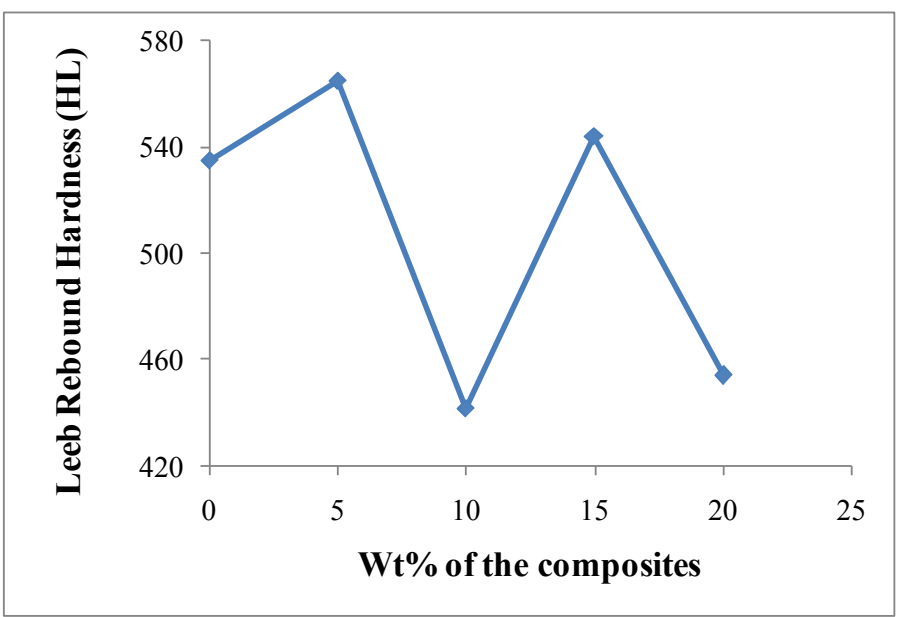

Figure 11. Effect of spathe fiber addition on Leeb's rebound hardness of recycled HDPE/ spathe fiber composites.

Table 2. Effect of fiber addition on mechanical properties of coconut spathe reinforced recycled HDPE composite.

\begin{tabular}{ccccc}
\hline Composites & Tensile Strength (MPa) & $\begin{array}{c}\text { Flexural Strength } \\
(\mathrm{MPa})\end{array}$ & $\begin{array}{c}\text { Izod Impact } \\
\text { Strength (J/mm) }\end{array}$ & $\begin{array}{c}\text { Leeb's Rebound } \\
\text { Hardness (HL) }\end{array}$ \\
\hline C1 & 14.76 & 14.84 & 0.032 & 535 \\
C2 & 19.07 & 27.41 & 0.075 & 565 \\
C3 & 17.66 & 17.90 & 0.040 & 442.3 \\
C4 & 20.22 & 23.83 & 0.045 & 544 \\
C5 & 12.89 & 17.25 & 0.038 & 454 \\
\hline
\end{tabular}

\section{Conclusion}

In this present study, coconut spathe fiber reinforced with recycled high-density polyethylene composites was made to observe the different properties and also search the opportunity of HDPE/spathe fiber composites as a new engineering material, a new material that opens the door to new technologies, whether they are in civil, chemical, construction, nuclear, aeronautical, agricultural, mechanical, and biomedical or electrical engineering. Nowadays, an engineering material has a great choice because of its strength, its electrical properties, resistance to heat or corrosion, or a host of other reasons; but they all relate to properties. In this fabricated process, it is seen that with the increase of fiber addition, the density increases and follows the mixture rule. Water absorption of the spathe fiber reinforced HDPE composites was increased with time and fiber addition. Tensile properties, flexural properties, impact strength and hardness of composites were found to be increased with increasing fiber addition. And the value increased for $5 \%$ and $15 \%$ composites in most cases and the value decreased for $10 \%$ and $20 \%$ composites. From water absorption property, this research showed that composites with $5 \%$ and $15 \%$ fiber content absorbed less water comparatively than other compositions. Absorption of more water decreased some mechanical 
properties of the composites. Another reason is that maybe in 5\% and $15 \%$ compositions, the fibers are well distributed in the composites and the better interfacial bonding between the fiber and matrix for showing better results. Inclusion of fiber in HDPE/spathe fiber composites improved the load bearing capacity (tensile strength) and the ability to withstand bending (flexural strength) of the composites. But at the same time, in few cases with the addition of fiber in composites, these properties of the composites are found to be decreasing. This decline in strength may be attributed to the presence of pores at the interface between the spathe fibers and the matrix; the interfacial adhesion may be too weak to transfer the tensile stress. It was also revealed that HDPE/spathe fiber composites had moderate mechanical properties (such as tensile and flexural properties, impact strength and hardness).

\section{Conflicts of Interest}

The authors declare no conflicts of interest regarding the publication of this paper.

\section{References}

[1] Kabir, M.M., Wang, H., Lau, K.T. and Cardona, F. (2012) Chemical Treatments on Plant-Based Natural Fiber Reinforced Polymer Composites: An Overview. Composites Part. Engineering, 43, 2883-2892. https://doi.org/10.1016/j.compositesb.2012.04.053

[2] Mohanty, A.K., Misra, M. and Drzal, L.T. (2001) Surface Modifications of Natural Fibers and Performance of the Resulting Biocomposites: An Overview. Composite Interfaces, 8, 313-343. https://doi.org/10.1163/156855401753255422

[3] Cantero, G., Arbelaiz, A., Llano-Ponte, R. and Mondragon, I. (2003) Effects of Fiber Treatment on Wettability and Mechanical Behaviour of Flax/Polypropylene Composites. Composites Science and Technology, 63, 1247-1254. https://doi.org/10.1016/S0266-3538(03)00094-0

[4] Mohammed, L., Ansari, M.N.M., Pua, G., Jawaid, M. and Islam, M.S. (2015) A Review on Natural Fiber Reinforced Polymer Composite and Its Applications. International Journal of Polymer Science, 2015, Article ID: 243947. https://doi.org/10.1155/2015/243947

[5] Saba, N., Tahir, P.M. and Jawaid, M. (2014) A Review on Potentiality of Nano Filler/Natural Fiber Filler Polymer Hybrid Composites. Polymers, 6, 2247-2273. https://doi.org/10.3390/polym6082247

[6] Ahmed, F., Choi, H.S. and Park, M.K. (2014) Natural Fiber Composites Selection in View of Mechanical, Light Weight, and Economic Properties. Macromolecular Materials and Engineering, 300, 10-24. https://doi.org/10.1002/mame.201400089

[7] Du, Y., Wu, T., Yan, N., Kortschot, M.T. and Farnood, R. (2014) Fabrication and Characterization of Fully Biodegradable Natural Fiber-Reinforced Poly(Lactic Acid) Composites. Composites Part B: Engineering, 56, 717-723. https://doi.org/10.1016/j.compositesb.2013.09.012

[8] La Mantia, F.P. and Morreale, M. (2011) Green Composites, a Brief Review. Composites Part A, 42, 579-588. https://doi.org/10.1016/j.compositesa.2011.01.017

[9] Chen, R.S., Ghani, M.A., Hafizuddin, A., Sahrim, S.M. and Tarawneh, A. (2015) 
Mechanical, Water Absorption and Morphology of Recycled Blend Rice Husk Flour Bio-Composites. Journal of Applied Polymer Science, 132, 2461-2472. https://doi.org/10.1002/app.41494

[10] Panthania, D. and Singh, D. (2009) A Review on Electrical Properties of Fiber Reinforced Polymer Composites. International Journal of Theoretical and Applied Science, 1, 34-37.

[11] Lu, N., Sawn, R.H. and Ferguson, I. (2012) Composition, Structure and Mechanical Properties of Hemp Fiber Reinforced Composite with Recycled High Density Polyethylene Matrix. Journal of Composite Materials, 46, 1915-1924. https://doi.org/10.1177/0021998311427778

[12] Kumar, V., Kumar, S. and Kumar, R. (2012) Improved Mechanical and Thermal Properties of Bamboo-Epoxy Nanocomposites. Journal of Polymer Composites, 33, 362-370. https://doi.org/10.1002/pc.22155

[13] Li, X., Tabil, L.G. and Panigrahi, S. (2006) Chemical Treatments of Natural Fiber for Use in Natural Fiber-Reinforced Composites: A Review. Journal of Polymers and the Environment, 15, 25-33. https://doi.org/10.1007/s10924-006-0042-3

[14] Saheb, D.N. and Jog, J.P. (1999) Natural Fiber Polymer Composites: A Review. Advances in Polymer Technology, 18, 351-363. https://doi.org/10.1002/(SICI)1098-2329(199924)18:4<351::AID-ADV6>3.0.CO;2-X

[15] Biagiotti, J., Puglia, D., Torre, L., Kenny, J.M., Arbelaiz, A., Cantero, G., Marieta, C., Llano-Ponte, R. and Mondragon, I. (2004) A Systematic Investigation on the Influence of the Chemical Treatment of Natural Fibers on the Properties of Their Polymer Matrix Composites. Polymer Composites, 25, 470-479. https://doi.org/10.1002/pc.20040

[16] Kalia, S., Thakur, K., Celli, A., Kiechel, M.A. and Schauer, C.L. (2013) Surface Modification of Plant Fibers Using Environment Friendly Methods for Their Application in Polymer Composites, Textile Industry and Antimicrobial Activities: A Review. Journal of Environmental Chemical Engineering, 1, 97-112.

https://doi.org/10.1016/j.jece.2013.04.009

[17] Reddy, M., Vivekanandhan, S., Misra, M., Bhatia, S. and Mohanty, A.K. (2013) Biobased Plastics and Bio-Nanocomposites: Current Status and Future Opportunities. Progress in Polymer Science, 38, 1653-1689.

https://doi.org/10.1016/j.progpolymsci.2013.05.006

[18] (2006) Use of Coconut Fiber-Cement Board in House Construction. http://www.uplb.edu.ph

[19] Satyanarayana, K.G., Pillai, C.K.S., Sukumaran, K. and Pillai, S.G.K. (1982) Structure Property Studies of Fibers from Various Parts of the Coconut Tree. Journal of Materials Science, 17, 2453-2462. https://doi.org/10.1007/BF00543759

[20] Verma, D., Gope, P.C., Shandilya, A., Gupta, A. and Maheshwar, M.K. (2012) Coir Fiber Reinforcement and Application in Polymer Composites: A Review. Journal of Materials and Environmental Science, 4, 263-276.

[21] Oza, S., Wang, R. and Lu, N. (2011) Thermal and Mechanical Properties of Recycled High Density Polyethylene/hemp Fiber Composite. International Journal of Applied Science and Technology, 1, 31-36.

[22] Vijay Kumar, S., Ashwin Vishwanath, K., Nilavarasan, T., Prabhakar, S. and Usharani, R. (2013) Study of Mechanical Properties of Coconut-Spathe Fibers and Kneaf Bast Fiber Reinforced Epoxy Polymer Matrix Composites. 3rd International Conference on Recent Advances in Material Processing Technology (RAMPT13). 
[23] https://www.ihs.com/products/high-density-polyethylene-chemical-economics-han dbook.html

[24] Hamad, K., Kaseem, M. and Deri, F. (2013) Recycling of Waste from Polymer Materials: An Overview of the Recent Works. Polymer Degradation and Stability, 98, 2801-2812. https://doi.org/10.1016/j.polymdegradstab.2013.09.025

[25] Moazzem, K.G. (2016) Plastic Waste Management: In Search of an Effective Operational Framework. The Financial Express, 20 January.

[26] Ozalp, M. (2011) Study of the Effect of Adding the Powder of Waste PET Bottles and Borax Pentahydrate to the Urea Formaldehyde Adhesive Applied on Plywood. European Journal of Wood and Wood Products, 69, 369-374.

https://doi.org/10.1007/s00107-010-0439-5

[27] HDPE (High Density Polyethylene). http://www.upcinc.com/resources/materials/HDPE.html

[28] Chianelli-Junior, R., Reis, J.M.L., Cardoso, J.L. and Castro, P.F. (2013) Mechanical Characterization of Sisal Fiber-Reinforced Recycled HDPE Composites. Materials Research, 16, 1393-1397. https://doi.org/10.1590/S1516-14392013005000128

[29] Ibrahim, M.M., Dufresne, A., El-Zawawy, W.K. and Agblevor, F.A. (2010) Banana Fibers and Microfibrils as Lignocellulosic Reinforcements in Polymer Composites. Carbohydrate Polymers, 81, 811-819. https://doi.org/10.1016/j.carbpol.2010.03.057

[30] Rafia, A., Rajia, S., Md. Zahangir, A., Rakibul, Q., Ara, B. and Gafur, A. (2013) Fabrication and Characterization of Woven Natural Fibre Reinforced Unsaturated Polyester Resin Composites. International Journal of Engineering and Technology, 13, 122-128.

[31] Chotirat, L., Chaochanchaikul, K. and Sombatsompop, N.Ã. (2007) On Adhesion Mechanisms and Interfacial Strength in Acrylonitrile-Butadiene-Styrene/Wood Sawdust Composites. International Journal of Adhesion and Adhesives, 27, 669-678. https://doi.org/10.1016/j.ijadhadh.2007.02.001

[32] Kaseem, M., Hamad, K., Park, J.H. and Ko, Y.G. (2015) Rheological Properties of ABS/Wood Composites. European Journal of Wood and Wood Products, 73, 701-703. https://doi.org/10.1007/s00107-015-0928-7

[33] Threepopnatkul, P., Teppinta, W. and Sombatsompop, N. (2010) Effect of Co-Monomer Content on Rheological Property of Sawdust/ABS Composites. Advanced Materials Research, 93-94, 611-614. https://doi.org/10.4028/www.scientific.net/AMR.93-94.611

[34] Martins, J.N., Klohn, T.G., Bianchi, O., et al. (2010) Dynamic Mechanical, Thermal, and Morphological Study of ABS/Textile Fiber Composites. Polymer Bulletin, 64, 497-510. https://doi.org/10.1007/s00289-009-0200-6

[35] Mohammad, N.N.B. and Arsad, A. (2013) Mechanical, Thermal and Morphological Study of Kenaf Fiber Reinforced rPET/ABS Composites. Malaysian Polymer Journal, 8, 8-13.

[36] ASTM C134-95 (2016) Standard Test Methods for Size, Dimensional Measurements and Bulk Density of Refractory Brick and Insulating Firebrick. ASTM International, West Conshohocken.

[37] ASTM D570-98 (2018) Standard Test Method for Water Absorption of Plastics. ASTM International, West Conshohocken.

[38] Standard Test Method for Tensile Properties of Polymer Matrix Composite Materials (2014) Standard Test Method for Tensile Properties of Polymer Matrix Composite Materials. Annual Book of ASTM Standards, 1-13. 
[39] ASTM D6272-17 (2017) Standard Test Method for Flexural Properties of Unreinforced and Reinforced Plastics and Electrical Insulating Materials by Four-Point Bending. ASTM International, West Conshohocken.

[40] Budnikov, P.P. (1964) The Technology of Ceramic and Refractories. MIT Press, Cambridge.

[41] Khan, J.A., Khan, M.A., Islam, R. and Gafur, A. (2010) Mechanical, Thermal and Interfacial Properties of Jute Fabric-Reinforced Polypropylene Composites: Effect of Potassium Dichromate. Material Science and Application, 1, 350-357. https://doi.org/10.4236/msa.2010.16051

[42] Mishra, S., Naik, J.B. and Patil, Y.P. (2000) The Compatibilising Effect of Maleic Anhydride on Swelling and Mechanical Properties of Plant-Fiber Reinforced Novolac Composites. Composites Science and Technology, 60, 1729-1735. https://doi.org/10.1016/S0266-3538(00)00056-7

[43] Lee, S.-H. and Wang, S.Q. (2006) Biodegradable Polymers/Bamboo Fiber Biocomposite with Bio-Based Coupling Agent. Composites: Part A, 37, 80-91. https://doi.org/10.1016/j.compositesa.2005.04.015

[44] Lima, A., Monterio, S. and Satyanarayana, K. (2012) Recycled Polyethylene Composites Reinforced with Jute Fabric from Sackcloth: Part I Preparation and Preliminary Assessment. Journal of Polymer and the Environment, 20, 245-253. https://doi.org/10.1007/s10924-011-0373-6

[45] Neher, B., Bhuiyan, M.M.R., Kabir, H., Gafur, M.A., Oadir, M.R. and Ahmed, F. (2014) Study of Mechanical and Physical Properties of Palm Fiber Reinforced Acrylonitrile Butadiene Styrene Composites. Journal of Material Science and Application, 5, 39-45. https://doi.org/10.4236/msa.2014.51006

[46] Ahmad, I., Bakar, A. and Mokhilas, S.N. (2005) Recycled PET for Rice Husk/Polyester Composites. AJSTD, 22, 345-353. http://eprints.utp.edu.my/3294 https://doi.org/10.29037/ajstd.170

[47] Tan, C., Ahmad, I. and Heng, M. (2011) Characterization of Polyester Composites from Recycled Polyethylene Terephthalate Reinforced with Empty Fruit Bunch Fibers. Materials \& Design, 32, 4493-4501. https://doi.org/10.1016/j.matdes.2011.03.037

[48] Bhuiyan, A.H., Mina, M.F., Seema, S., Khan, M.M., Rahman, M.J. and Gafur, M.A. (2011) Structural, Elastic and Thermal Properties of Titanium Dioxide Filled Isotactic Polypropylene. Journal of Polymer Research, 18, 1073-1079. https://doi.org/10.1007/s10965-010-9509-y

[49] Rahman, M.M. and Khan, M.A. (2007) Surface Treatment of Coir Fibers and Its Influence on the Fibers Physico-Mechanical Properties. Composites Science and Technology, 67, 2369-2376. https://doi.org/10.1016/j.compscitech.2007.01.009 